\title{
Determination of gestational age by measuring defined embryonic and foetal indices with ultrasonography in Abaza and Gurcu goats
}

\author{
Mushap Kuru ${ }^{1}$, Hasan Oral ${ }^{1}$, Recai Kulaksiz ${ }^{2}$ \\ ${ }^{1}$ Kafkas University, Faculty of Veterinary Medicine, Department of Obstetrics and Gynaecology, Kars, Turkey \\ ${ }^{2}$ Balikesir University, Faculty of Veterinary Medicine, Department of Reproduction and Artificial Insemination, \\ Balikesir, Turkey
}

Received November 30, 2017

Accepted December 7, 2018

\begin{abstract}
The aim of this study was to determine gestational age in Abaza and Gurcu goats by measuring certain embryonic and foetal indices with ultrasonography. A 5-7.5 MHz linear probe was used to obtain ultrasound measurements from 30 pregnant goats (10 Abaza and $20 \mathrm{Gurcu})$. Heart diameter (HD), biparietal diameter (BPD), crown-rump length (CRL), trunk diameter (TD) and placentome diameter (PD) were measured to determine gestational age. The mean of embryonic and foetal indices were calculated and linear regression was performed. Heart diameter measurements for Abaza and Gurcu goats were significantly different on days $45(P=0.048)$ and $60(P=0.019)$. Biparietal diameter values were significantly different on day $45(P=0.035)$. Crown-rump length measurements were significantly different at days $30(P=0.003)$ and $60(P=0.002)$. We determined that HD and TD were the best predictors of gestational age for Abaza goats $\left(\mathrm{R}^{2}=0.952, \mathrm{R}^{2}=0.949\right.$, respectively), whereas HD and CRL were the best predictors of gestational age for Gurcu goats $\left(\mathrm{R}^{2}=0.933, \mathrm{R}^{2}=0.942\right.$, respectively). Based upon our study results, these specific indices could be applied during ultrasonographic examinations of Abaza and Gurcu goats to confirm gestational age when the day of mating is unknown.
\end{abstract}

Goat, heart diameter, crown-rump length

Abaza and Gurcu goats, which are important Turkish genetic resources, are raised locally in Northeastern Anatolia. These goats have adapted to the particularly cold climate conditions of the region. To date, very few studies have been conducted on the reproductive characteristics of these animals (Batu 1951; Yalçın 1988; Kuru et al. 2017a; 2017b).

Considering the conditions of the meadows, the exact mating day of sheep and goats are typically unknown. Thus, gestational age is not generally precisely determined in these animals. Since pregnant and non-pregnant animals require different care and feeding regimes, ultrasonographic methods have been used in the past to estimate gestational age (Haibel 1988; Haibel et al. 1989; Doize et al. 1997; Karen et al. 2009).

B-mode ultrasonography is a fast and reliable method used to check for pregnancy in small ruminants. Transrectal ultrasonography is significantly better than the transabdominal method in obtaining more accurate results during the early gestational period (days 27-30) (Ishwar 1995; Doize et al. 1997; Gürler and Kaymaz 2011; Karadaev et al. 2016).

Today, it is possible to determine gestational age in humans by measuring the biparietal diameter (BPD). Similarly, there are reported studies conducted in sheep and goats using BPD measurements (Haibel 1988; Haibel et al. 1989; Reichle and Haibel 1991; Lee et al. 2005). In addition to BPD, gestational age may also be determined by measuring the heart diameter (HD), placentome diameter (PD), crown-rump length (CRL), trunk diameter (TD), the aorta, or the umbilical cord (Martinez et al. 1998; Lee et al. 2005; Amer 2010; Kandiel et al. 2015).

Address for correspondence:

Mushap Kuru

Department of Obstetrics and Gynecology

Faculty of Veterinary Medicine

Phone: $+904742426807 / 5218$

Kafkas University, 36100 Kars, Turkey 
This study was designed to measure the HD, BPD, CRL, TD and PD by real-time ultrasonography in Abaza and Gurcu goats to determine gestational age based upon these embryonic and foetal measurements. In addition, differences between the foetal biometry of Abaza and Gurcu goats were determined.

\section{Materials and Methods}

Animals and oestrus synchronization

This study was conducted upon obtaining approval from the Kafkas University Animal Experiments Local Ethics Committee, Kars, Turkey (KAÜ-HADYEK -2015/012).

The study population consisted of 15 Abaza and 30 Gurcu goats 3-5 years of age weighing $50-60 \mathrm{~kg}$. Oestrus synchronization was initiated during the breeding season. Sponges containing progesterone $(60 \mathrm{mg}$, medroxyprogesterone acetate, Esponjavet ${ }^{\mathbb{}}$, Hipra, Turkey) were placed intravaginally. On day 9 , all goats were treated with $400 \mathrm{IU}$ equine chorionic gonadotropin (IM, eCG, Folligon ${ }^{\circledR}$, İntervet, Turkey) and $5 \mathrm{mg}$ dinoprost tromethamine (IM, Dinolytic ${ }^{\circledR}$, Zoetis, Turkey). The sponges were removed on day 11. Following synchronization, a teaser buck was introduced to the herd to monitor oestral activity. The goats determined to be in oestrus were mated with 9 fertility-proven bucks (4 Abaza and 5 Gurcu). The mating times were recorded for reference during future ultrasonographic examinations.

\section{Ultrasonographic examinations}

Embryonic and foetal measurements were performed in 30 goats ( 10 Abaza, 20 Gurcu) diagnosed as pregnant. Measurements were performed on days 30,45, 60,75, 90 and 120 of gestation. Transrectal ultrasonography was used for the measurements performed on day 30 , while the remaining measurements were performed using transabdominal ultrasonography (5-7.5 MHz, SonoSite Titan ${ }^{\circledR}$, SonoSite, WA, USA). When clear images could not be obtained using transabdominal ultrasonography on day 45 , transrectal ultrasonography was used. To increase the quality of ultrasound imaging and prevent artifacts, the animals were restrained during transrectal ultrasonography. Faeces were removed from the rectum using lubricant and transrectal ultrasonography was initiated with the goats in standing position. During transabdominal examinations, the animals were positioned in dorsal recumbency, and an area of $5 \mathrm{~cm}$ in width by $12 \mathrm{~cm}$ in length inferior to the breast was shaved. Ultrasound imaging of the area was performed after it was cleaned with alcohol and cotton. Ultrasound gel was used for both transrectal and transabdominal ultrasonography to facilitate obtaining clearer images.

Gestational ultrasonography measurements were taken at 30, 45, 60, 75, 90 and 120 days for HD, at 30, 45, 60,75 and 90 days for BPD and TD, at 30, 45, 60 and 75 days for CRL, and at 45, 60, 75, 90 and 120 days for PD. On day 75, CRL could only be measured in 13 Gurcu goats due to excessive growth of the foetus (CRL was measured in 10 Abaza goats). This number was taken into consideration during calculation of the mean number and statistical assessment.

As suggested by Lee et al. (2005) and Oral et al. (2007), HD was measured by freezing the image at the heart's widest point of expansion and recording the diameter; BPD measurements were performed by freezing the image at the best angle to measure the width, as suggested by Haibel (1988) and Amer (2010); CRL measurements were performed as suggested by Kaulfuss et al. (1999) and Martinez et al. (1998); TD measurements were performed by detecting the diaphragm limit (Karen et al. 2009). For placentome measurements, once the desired image was displayed on the monitor, the image was frozen and dimensions were taken using the calipers of the ultrasound device. The average of the three largest placentomes captured in the image was recorded (Lee et al. 2005; Karen et al. 2009).

\section{Statistical analysis}

Statistical analysis was performed using SPSS ${ }^{\circledR}$ software (SPSS 16.0, IL, USA). Group averages (the embryonic and foetal average) were determined and linear regression was performed using the gestational age formula $' \mathrm{y}=\mathrm{ax}+\mathrm{b}$ ', where $\mathrm{y}=$ gestational age, $\mathrm{a}=$ predictors (constant), $\mathrm{x}=$ measured value, and $\mathrm{b}=$ dependent variable. Additionally, the statistical difference between the groups was calculated using Student's $t$-test. $P<0.05$ was accepted as significant. The values obtained were presented as mean \pm standard deviation (SD).

\section{Results}

There were 5 twin (2 Abaza and 3 Gurcu) and 25 single (8 Abaza and 17 Gurcu) births. The HD measurements for Abaza and Gurcu goats were significantly different on days $45(P=0.048)$ and $60(P=0.019)$. The BPD values were significantly different on day $45(P=0.035)$. The CRL measurements were significantly different on days $30(P=0.003)$ and $60(P=0.002)$. The TD and PD measurements were significantly different on day $75(P=0.041$ and $P=0.005$, respectively, Table 1$)$. Based on the data, 
Table 1. Embryonic and foetal measurements (mean \pm standard deviation) in Abaza and Gurcu goats performed on days $30,45,60,75,90$ and 120 using ultrasound.

\begin{tabular}{|c|c|c|c|c|c|c|c|c|}
\hline \multirow{2}{*}{$\begin{array}{l}\text { Variables } \\
(\mathrm{cm})\end{array}$} & \multirow{2}{*}{ Goat } & \multirow{2}{*}{$\mathrm{n}$} & \multicolumn{6}{|c|}{ Gestation Day } \\
\hline & & & Day 30 & Day 45 & Day 60 & Day 75 & Day 90 & Day 120 \\
\hline \multirow[t]{2}{*}{ HD } & Abaza & 10 & $0.3 \pm 0.1$ & $0.6 \pm 0.1^{\mathrm{a}}$ & $0.8 \pm 0.2^{\mathrm{a}}$ & $1.3 \pm 0.1$ & $1.9 \pm 0.2$ & $3.1 \pm 0.1$ \\
\hline & Gurcu & 20 & $0.3 \pm 0.1$ & $0.7 \pm 0.1^{b}$ & $1.0 \pm 0.2^{b}$ & $1.3 \pm 0.1$ & $1.9 \pm 0.4$ & $3.1 \pm 0.2$ \\
\hline \multirow[t]{2}{*}{ BPD } & Abaza & 10 & $0.7 \pm 0.1$ & $1.1 \pm 0.1^{\mathrm{a}}$ & $1.9 \pm 0.1$ & $2.9 \pm 0.6$ & $3.5 \pm 0.3$ & - \\
\hline & Gurcu & 20 & $0.6 \pm 0.1$ & $1.0 \pm 0.2^{b}$ & $1.9 \pm 0.3$ & $2.6 \pm 0.4$ & $3.6 \pm 0.3$ & - \\
\hline \multirow[t]{2}{*}{ CRL } & Abaza & 10 & $1.7 \pm 0.2^{\mathrm{c}}$ & $3.0 \pm 0.7$ & $6.5 \pm 0.5^{\mathrm{c}}$ & $9.2 \pm 1.3$ & - & - \\
\hline & Gurcu & 20 & $1.6 \pm 0.3^{\mathrm{d}}$ & $3.3 \pm 0.6$ & $7.2 \pm 0.6^{\mathrm{d}}$ & $9.9 \pm 0.9^{\#}$ & - & - \\
\hline \multirow[t]{2}{*}{ TD } & Abaza & 10 & $0.6 \pm 0.1$ & $1.6 \pm 0.2$ & $2.3 \pm 0.3$ & $3.7 \pm 0.4^{\mathrm{a}}$ & $4.6 \pm 0.3$ & - \\
\hline & Gurcu & 20 & $0.7 \pm 0.2$ & $1.6 \pm 0.4$ & $2.2 \pm 0.3$ & $3.4 \pm 0.4^{\mathrm{b}}$ & $4.6 \pm 0.5$ & - \\
\hline \multirow[t]{2}{*}{ PD } & Abaza & 10 & - & $1.1 \pm 0.1$ & $1.8 \pm 0.2$ & $2.1 \pm 0.2^{\mathrm{c}}$ & $2.8 \pm 0.3$ & $3.4 \pm 0.2$ \\
\hline & Gurcu & 20 & - & $1.0 \pm 0.3$ & $1.9 \pm 0.2$ & $2.4 \pm 0.2^{\mathrm{d}}$ & $2.8 \pm 0.3$ & $3.5 \pm 0.1$ \\
\hline
\end{tabular}

HD - heart diameter; BPD - biparietal diameter; CRL - crown-rump length; TD - trunk diameter; PD - placentome diameter; superscripts a and b show the $P$ value between Abaza and Gurcu goats: $P<0.05$; superscripts $\mathrm{c}$ and d show the $P$ value between Abaza and Gurcu goats: $P<0.01$; * only 13 goats were measured on day 75 .

HD and TD were determined to be the best predictors of gestational age for Abaza goats $\left(\mathrm{R}^{2}=0.952\right.$ and $\mathrm{R}^{2}=0.949$, respectively), whereas HD and CRL were the best predictors of gestational age for Gurcu goats $\left(\mathrm{R}^{2}=0.933\right.$ and $\mathrm{R}^{2}=0.942$, respectively, Fig. 1).

\section{Discussion}

Embryonic heart rate can be detected at 19-20 days post-mating (Medan et al. 2004; Padilla-Rivas et al. 2005) and measured at 22-36 days post-mating (Karen et al. 2009). It has been reported that the HD of sheep and goats can be detected at 30-40 days of gestation; however, no measurements were performed (Raja et al. 2011). The measurements in this study were taken from day 30 of gestation onwards. In the assessment performed, it was determined that embryonic or fetal HD could be used to determine gestational age as there was a high correlation between embryonic and fetal HD values and gestational age. Moreover, HD measurements were found to be the best predictors of gestational age in Abaza and Gurcu goats. These findings were comparable with the results reported by previous studies (Greenwood et al. 2002; Lee et al. 2005; Oral et al. 2007; Gunduz et al. 2010; Kandiel et al. 2015).

Biparietal diameter measurements with ultrasonography are commonly used to determine foetal age in humans (Kieler et al. 1995; Sailaja et al. 1996). In studies conducted with sheep and goats, the correlation between BPD measurements at 32-90 days of gestation and determination of gestational age was $r \geq 0.96$ (Haibel 1988; Gonzalez de Bulnes et al. 1998; Nwaogu et al. 2010). In studies conducted with different goat breeds (Toggenburg, Nubian, Angora), a high correlation was found between BPD and gestational age $\left(\mathrm{R}^{2}=0.994, \mathrm{R}^{2}=0.988, \mathrm{R}^{2}=0.978\right.$, respectively) (Haibel et al. 1989). Our study also found a high correlation between BPD and gestational age at 30-90 days of gestation for Abaza and Gurcu goats. However, the obtained $\mathrm{R}^{2}$ values $\left(\mathrm{R}^{2}=0.925\right.$ for Abaza goats, $\mathrm{R}^{2}=0.928$ for Gurcu goats) were lower than those previously reported, which may be due to breed differences.

Crown-rump length measurements can be easily performed at 20-50 days of gestation in small ruminants (Schrick and Inskeep 1993; Kaulfuss et al. 1999; Godfrey 

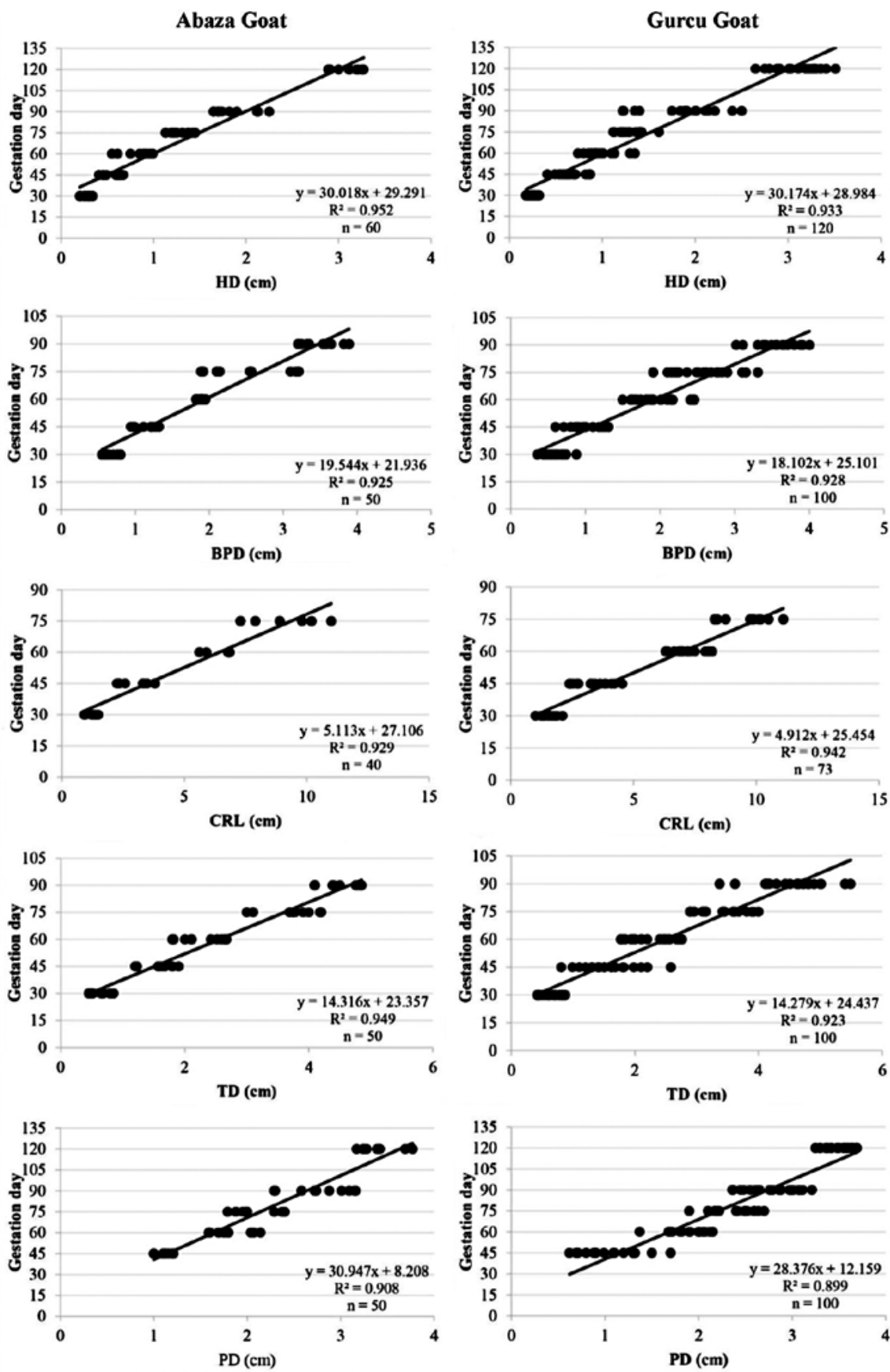

Fig 1. Regression curve indicating the correlation between embryonic and foetal heart diameter (HD, $\mathrm{cm}$ ), biparietal diameter (BPD, $\mathrm{cm}$ ), crown-rump length $(\mathrm{CRL}, \mathrm{cm})$, trunk diameter $(\mathrm{TD}, \mathrm{cm})$, placentome diameter $(\mathrm{PD}, \mathrm{cm})$ and gestational age (day) in Abaza and Gurcu goats; $\mathrm{n}$ - number of total measurements; $\mathrm{y}$ - gestational age; $\mathrm{x}$ - measured value 
et al. 2010). A strong positive correlation was found between CRL and determination of gestational age in studies conducted with Saanen goats $\left(\mathrm{R}^{2}=0.90\right.$ ) (Abdelghafar et al. 2011). Accordingly, a high correlation has been reported between CRL in Egyptian Baladi goats at 25-70 days of gestation (Karen et al. 2009) and Anglo-Nubian goats at 19-40 days of gestation (Martinez et al. 1998). Similarly, there was a high correlation between CRL and determination of early gestational age in Abaza goats $\left(\mathrm{R}^{2}=0.929\right)$ and Gurcu goats $\left(\mathrm{R}^{2}=0.942\right)$ in our study. The CRL measurements could only be performed until day 75 of gestation as the foetus then grew too large for the display, making measurements impossible in the subsequent days. Nevertheless, CRL is the best predictor of gestational age in Gurcu goats. A study conducted by Amer (2010) reported that CRL measurements were not possible after day 89 of gestation.

In goats, gestational age reportedly could be determined by measuring embryonic and foetal TD using ultrasonography at 30-120 days (Karen et al. 2009; Kandiel et al. 2015) or 60-135 days (Lee et al. 2005) of gestation. The correlation found between TD and gestational age by Lee et al. (2005) was $\mathrm{r}=0.887$, whereas the correlation found by Karen et al. (2009) was $\mathrm{R}^{2}=0.962$. In our study, there was a high correlation at days $30-90$ of gestation between TD and gestational age for Abaza $\left(\mathrm{R}^{2}=0.949\right)$ and Gurcu goats $\left(\mathrm{R}^{2}=0.923\right)$. The data we obtained were comparable with those reported previously (Lee et al. 2005; Karen et al. 2009; Kandiel et al. 2015), and the fact that TD measurements are easier than the other foetal index measurements demonstrated that TD could be the preferred measurement for determining gestational age in goats, especially during ultrasonographic examination performed in Abaza goats.

In a study conducted by Karen et al. (2009), placentomes were detectable as small echogenic nodules as of day 28 of gestation. In our study, no exact measurement could be made on day 30; therefore, the measurements were taken on day 45. In several studies, a weak positive correlation was found between PD and gestational age in goats (Doize et al. 1997; Lee et al. 2005; Nwaogu et al. 2010). In our study, there was a high correlation $(P<0.001)$ between the placentome diameter and gestational age in Abaza and Gurcu goats. Our findings were similar to those of Karen et al. (2009) $\left(\mathrm{R}^{2}=0.905\right)$ and Kandiel et al. (2015) $\left(\mathrm{R}^{2}=0.899\right)$ and higher than those of Lee et al. (2005) $(\mathrm{r}=0.574)$, Nwaogu et al. (2010) $(\mathrm{r}=0.45)$ and Doize et al. (1997) $\left(\mathrm{R}^{2}=0.703\right)$. These differences may have resulted from the variance in placentome sizes and goat breeds. Additionally, using the largest placentomes on the display may have increased the correlation rate with gestational age.

In conclusion, a high correlation was found between gestational ages and HD, BPD, CRL, TD and PD measured by real-time ultrasonography. Also, HD, BPD, CRL, TD and PD values were significantly different on different gestational days for Abaza and Gurcu goats. The HD and TD for Abaza goats and the HD and CRL for Gurcu goats were the best predictors of gestational age in this study. Based on our results, these indices could be beneficial in determining gestational ages of these breeds using ultrasonography when precise mating times are unknown due to field conditions.

\section{Acknowledgements}

This study was supported by Kafkas University and Scientific Research Projects Coordination Unit, Kars, Turkey (Project number: 2015-TS-35).

\section{References}

Abdelghafar RM, Ahmed BH, Ibrahim MT, Mantis P 2011: Prediction of gestational age by transabdominal real-time ultrasonographic measurements in Saanen goats (Capra hircus). Glob Vet 6: 346-351

Amer HA 2010: Ultrasonographic assessment of early pregnancy diagnosis, fetometry and sex determination in goats. Anim Reprod Sci 117: 226-231 
Batu S 1951: Turkish Goat Breeds. Ankara Üniversitesi Veteriner Fakültesi Yayınları, Ankara, (Book in Turkish)

Doize F, Vaillancourt D, Carabin H, Bélanger D 1997: Determination of gestational age in sheep and goats using transrectal ultrasonographic measurement of placentomes. Theriogenology 48: 449-460

Godfrey RW, Larson L, Weis AJ, Willard ST 2010: Evaluation of ultrasonography to measure fetal size and heart rate as predictors of fetal age in Hair sheep. Sheep Goat Res J 25: 60-65

Gonzalez de Bulnes A, Santiago MJ, Lopez SA 1998: Estimation of fetal development in Manchega dairy ewes by transrectal ultrasonographic measurements. Small Rumin Res 27: 243-250

Greenwood PL, Slepetis RM, McPhee MJ, Bell AW 2002: Prediction of stage of pregnancy in prolific sheep using ultrasound measurement of fetal bones. Reprod Fertil Dev 14: 7-13

Gunduz MC, Turna O, Ucmak M, Apaydin S, Kasikci G, Ekiz B, Gezer NI 2010: Prediction of gestational week in Kivircik ewes using fetal ultrasound measurements. Agric J 5: 110-115

Gürler H, Kaymaz M 2011: Determination of embryonic and fetal age by transrectal and transabdominal ultrasonographic examination in Akkaraman ewes. Ankara Üniv Vet Fak Derg 58: 99-104

Haibel GK 1988: Real-time ultrasonic fetal head measurement and gestational age in dairy goats. Theriogenology 30: $1053-1057$

Haibel GK, Perkins NR, Lidl GM 1989: Breed differences in biparietal diameters of second trimester Toggenburg, Nubian and Angora goat fetuses. Theriogenology 32: 827-834

Ishwar AK 1995: Pregnancy diagnosis in sheep and goats. Small Rumin Res 17: 37-44

Kandiel MM, Watanabe G, Taya K 2015: Ultrasonographic assessment of fetal growth in miniature "Shiba" goats (Capra hircus). Anim Reprod Sci 162: 1-10

Karadaev M, Fasulkov I, Vassilev N, Petrova Y, Tumbev A, Petelov Y 2016: Ultrasound monitoring of the first trimester of pregnancy in local goats through visualization and measurements of some biometric parameters. Bulg J Vet Med 19: 209-217

Karen AM, Fattouh el-SM, Abu-Zeid SS 2009: Estimation of gestational age in Egyptian native goats by ultrasonographic fetometry. Anim Reprod Sci 114: 167-174

Kaulfuss KH, Uhlich K, Gille U 1999: Ultrasonographic examinations of fetal growth of sheep between day 20 and day 50 of gestation. Dtsch Tierarztl Wochenschr 106: 433-438

Kieler H, Axelsson O, Nilsson S, Waldenström U 1995: The length of human pregnancy as calculated by ultrasonographic measurement of the fetal biparietal diameter. Ultrasound Obstet Gynecol 6: 353-357

Kuru M, Kuru Boğa B, Kulaksiz R, Ari UÇ, Oral H 2017a: Effects of the progesterone-based estrus synchronization on some reproductive parameters in Abaza goats. Kocatepe Vet J 10: 164-171

Kuru M, Kuru Boğa B, Kulaksız R, Oral H 2017b: Some reproductive features of Gurcu goats. Harran Üniv Vet Fak Derg 6, 119-125

Lee Y, Lee O, Cho J, Shin H, Choi Y, Shim Y, Choi W, Shin H, Lee D, Lee G, Shin S 2005: Ultrasonic measurement of fetal parameters for estimation of gestational age in Korean black goats. J Vet Med Sci 67: 497-502

Martinez MF, Bosch B, Bosch RA 1998: Determination of early pregnancy and embryonic growth in goats by trans-rectal ultrasound scanning. Theriogenology 49: 1555-1565

Medan M, Watanabe G, Absy G, Sasaki K, Sharawy S, Taya K 2004: Early pregnancy diagnosis by means of ultrasonography as a method of improving reproductive efficiency in goats. J Reprod Dev 50: 391-397

Nwaogu IC, Anya KO, Agada PC 2010: Estimation of foetal age using ultrasonic measurements of different foetal parameters in red Sokoto goats (Capra hircus). Vet Arhiv 80: 225-233

Oral H, Pancarci SM, Gungor O, Kacar C 2007: Determination of gestational age by measuring fetal heart diameter with transrectal ultrasonograph in sheep. Med Weter 63: 1558-1560

Padilla-Rivas GR, Sohnrey B, Holtz W 2005: Early pregnancy detection by real-time ultrasonography in Boer goats. Small Rumin Res 58: 87-92

Raja I, Mohd Nizam AR, Abdullah RB, Wan Khadijah WE 2011: Using fetal-heart size measured from ultrasound scanner images to estimate age of gestation in goat. J Anim Vet Adv 10: 2528-2540

Reichle JK, Haibel GK 1991: Ultrasonic biparietal diameter of second trimester Pygmy goat fetuses. Theriogenology 35: 689-694

Sailaja K, Ahuja RK, Gopinath G 1996: Biparietal diameter: A useful measure for determining gestational age of human abortuses. Natl Med J India 9: 165-167

Schrick FN, Inskeep EK 1993: Determination of early pregnancy in ewes utilizing transrectal ultrasonography. Theriogenology 40: 295-306

Yalçın C 1988: Animal Breeding (Sheep and Goat), İstanbul Üniversitesi Yayınları, İstanbul (Book in Turkish) 